\title{
Application of Irregular Flowing Water Construction in Architectural Garden Project Management
}

\author{
Xiuyun, Li \\ Guangzhou Nanyang Polytechnic, Architectural Engineering Department, Guangzhou, Guangdong, 510900, China.
}

\begin{abstract}
Irregular flowing water construction is the common way of the construction of the garden project. On the basis of elaborating the form of flow water construction, the paper focuses on the general method of irregular flowing water construction, especially in the calculation of activity-on-arrow network, the garden project also needs to be introduced in the form of virtual work, in order to achieve the clear logic of the construction process and continuous construction.
\end{abstract}

\section{Introduction}

Architectural Garden engineering projects often involve the terrain, main structure, drainage, equipment and other sub sectors. Also the project should consider the engineering features such as architectural modeling, plant landscaping, culture and art, and further demonstrate the highly unified functions of biology, engineering and art. The construction organization design of garden engineering provides the basis for the construction unit or the supervision unit to compile the project plan, so as to effectively maintain the construction coordination, balance and civilization, and make a comprehensive strategic plan for the whole project. Therefore, scientific and reasonable arrangement of labor, materials, machinery and equipment, funds and construction methods, the five major construction factors $^{[1]}$, is an important means to develop effective construction organization design. This method makes garden engineering construction management more scientific and targeted, and garden engineering projects can show the characteristics of the times, which has practical value in construction.

Flow construction is the specific application of flow production in project organization. It is derived from "flow production" and "water production", which is an effective way of organizing production, and has been widely applied in light industry and heavy industry. The relationship between the flowing rhythm and the flow time in construction is always the focus of the management of water construction organization ${ }^{[2]}$. Flow construction organization is mainly to solve work stoppages (idle resources) and intermittent problem (idle working surface) in the construction work ${ }^{[3]}$. Therefore, flow construction has the characteristics of short time period, balanced resource consumption and high efficiency, which is beneficial to improving the economic benefit of comprehensive garden engineering.

\footnotetext{
${ }^{*}$ Corresponding author: ${ }^{a}$ sueone921@163.com
}

\section{The form of flowing construction}

For a garden engineering project, the overall arrangement of process construction, time arrangement and space layout will bring considerable economic benefits to the project department. Considering the professional requirements of gardening facilities, components and landscape sketches, plus the strict connection of construction process, reasonable layout of construction work surface and balanced utilization of resources, the common way of flow construction is generally adopted. Among the three major methods of construction, such as sequential construction, parallel construction and flow construction, the most straightforward and concise way to express flow construction is bar charts or vertical charts, which is usually combined with the network diagram.

In order to explain the working status of each construction process in time and space in detail, the preconditions for the construction of flowing construction need to introduce the state parameters used to describe the process flow, space layout and time arrangement.

First, in order to make the proposed garden project proceed smoothly, it is usually necessary to decompose the project. Then, the process parameters need to be introduced, mainly including the number of construction processes " $n$ " and the flow intensity " $t$ ". A garden project needs to determine the number of the construction process, there is no uniform regulation, which is related to the characteristic of the construction plan, the construction quantity, the construction team, the construction habit, the construction content and the scope, and strives to dominate the construction process and to be simple express the integrity of a project. Flow intensity is also known as flow capacity or production capacity, mechanical construction and artificial construction are two kinds of water flow intensity. 
Second, during the construction of the project, in order to divide the huge construction body, the work should be carried out in an orderly manner in the spatial arrangement, which is mainly expressed by three spatial parameters, namely, the work surface " $\mathrm{j}$ ", the construction layer and the construction section " $m$ ". The work surface reflects the sequence of mechanical arrangement in the construction process and the possibility that the working width of the workers is arranged in space. When determining the working face, it is generally strict with the relevant provisions of construction specifications and safety technology, and the work surface directly affects the organization of flow construction. Dividing the construction section allows the adjacent professional team to provide the work surface as soon as possible and enhance the work efficiency. It is noteworthy that when the construction of the garden project, especially the large-scale threedimensional modeling, involves multi-level or high-level architecture landscape sketches, it is necessary to divide the construction section on the plane, but also to divide the construction layer on the vertical direction so as to ensure the rhythmic construction.

Third, under the premise of construction method, construction machinery and working face permissible, then it needs to introduce the time parameters, the main

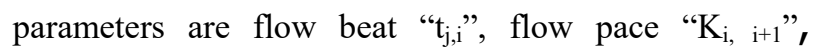
interval and joining time, and construction period " $\mathrm{T}$ ". Flow beat is one of the main time parameters, which needs to check the construction machinery, labor and material supply possibilities, but also needs to consider the construction methods and sufficient work surface and other factors. In order to cooperate with the flow rhythm organization, to determine the size of flow pace is necessary. In general, it should be satisfied to keep the process in a reasonable order and as much as possible continuous operation. In order to effectively connect work processes, it is usually required that sufficient intermittent time and overlapping time on the construction section, which ensure the quality standards of the proposed project, respectively, with technical interval time " $\mathrm{Z}_{\mathrm{i}, \mathrm{i}+1}$ ", organizing interval time " $\mathrm{G}_{\mathrm{i}, \mathrm{i}+1}$ " and parallel joining time " $\mathrm{C}_{\mathrm{i}, \mathrm{i}+\mathrm{1}}$ " three parameters to express. The construction period of flow construction generally refers to the entire duration of the construction of the first professional task force from the beginning of construction to the completion of construction by the last professional task force. Since a construction project often contains a number of flow groups, the construction period of a construction flow is not the total construction period of the whole project. Generally speaking, $\boldsymbol{T}=\sum \boldsymbol{K}_{i, i+1}+\boldsymbol{T}_{N}$ is used to represent the total construction period, $\sum K_{i, i+1}$ is the sum of each flow pace in flow construction, and $\boldsymbol{T}_{N}$ is the duration of the last construction process in flow construction. The formula has strong applicability and reflects the relationship and restriction between parameters. The determination of flowing water construction parameters has laid a foundation for the overall arrangement of construction organization design. The construction management of gardens is a systematic work, which requires respecting the objective laws and arranging in a scientific manner in order to reflect better technical and economic results.

\section{Garden engineering examples of irregular flowing water construction}

In the organization mode of flow water construction, there are two kinds of organization methods: regular beat flow construction and irregular flowing water construction. In the regular beat flow construction, it is often used in two ways. One is congruence beat flow construction, the other is equal pace or asynchronous pace of different rhythmic flow construction.

With regard to construction organization design tasks around plan, such as less labor, shorter construction period in schedule, high precision, good function in quality and low cost and high efficiency in economy, irregular flowing water construction method has become a common way to carry out the construction of garden works. In engineering practice, although the rhythm of flowing water varies greatly with the regularity of flowing water and the majority of flowing water steps, it is easy to cause the process to stop or advance the process. However, there is a certain functional relationship between the flow beat and flow pace, all professional teams do not work stoppages, and the schedule of construction is more flexible and free, which has been popularized and applied in garden engineering construction. Meanwhile, the research on different rhythmic non-intermittent flow construction and conditions and differences in non-intermittent construction period has practical significance for guiding the actual project construction management, which can not only improve managers' initiative of optimizing construction period, but also enrich and supplement organization and management of the basic theory of flow construction $^{[4]}$.

The calculation steps of regular beat flow construction and irregular flowing water construction is similarly. The first step is to determine the starting point, construction sequence, construction process, construction period; the second step is the calculation of flow beat and flow pace, in this way the flow pace of irregular flowing water construction is from Pantokovsky method; the last is to calculate the construction period and drawing schedule. The following is a garden project of irregular flowing water construction example.

According to the residential gardening project contract, four pavilions of the same scale and style must be built, and the flow beat and construction sections of the water flow in each construction process of the garden project are shown in Table 1. Calculate the flow pace and duration, and draw the construction schedule. 
Table 1: The flow beat and construction sections of the gardening project

\begin{tabular}{|c|c|c|c|c|}
\hline \multirow{2}{*}{ Construction Process } & \multicolumn{5}{|c|}{ Construction Sections } \\
\cline { 2 - 5 } & (1) & (2) & (3) & (4) \\
\hline Foundation excavation A & 3 & 5 & 3 & 4 \\
\hline Main body structure B & 2 & 3 & 2 & 3 \\
\hline Interior and exterior decoration C & 4 & 5 & 3 & 5 \\
\hline Peripheral greening D & 3 & 4 & 2 & 3 \\
\hline
\end{tabular}

From the analysis of Table 1, it should carry out irregular flowing water construction.

(1) To determine the flow construction from $\mathrm{A} \rightarrow \mathrm{B}$ $\rightarrow \mathrm{C} \rightarrow \mathrm{D}$, the number of construction sections is $\mathrm{m}=4$;

(2) To determine the number of construction process: it can be seen from the table $n=4$;

(3) Seeking the flow pace, using the "Largest difference method for the dislocation subtraction of accumulative series" to find the adjacent construction process flow pace, the list is summarized in Table 2; from the calculation shows that the construction process of foundation excavation $\mathrm{A}$ and the main structure B's flow pace is 8 , that is, $\mathrm{K}_{\mathrm{A}, \mathrm{B}}=8$; the same token that $\mathrm{K}_{\mathrm{B}, \mathrm{C}}$ $=2, \mathrm{~K}_{\mathrm{C}, \mathrm{D}}=8$.

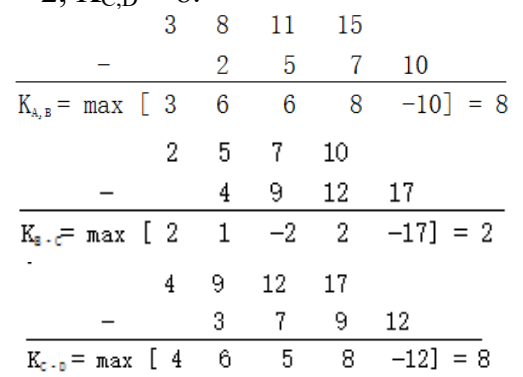

Table 2: Flow pace calculations for the case

\begin{tabular}{|c|c|c|c|c|c|c|c|c|c|}
\hline Name & & & & Value & & & & $\begin{array}{c}\text { The maximum } \\
\text { value in the }\end{array}$ & Flow \\
\hline $\begin{array}{l}\text { Accumulated value of flow beat in } \\
\text { construction process A }\end{array}$ & 3 & 8 & 11 & 15 & & & & & \\
\hline $\begin{array}{l}\text { Accumulated value of flow beat in } \\
\text { construction process B }\end{array}$ & & 2 & 5 & 7 & 10 & & & & \\
\hline $\begin{array}{l}\text { Accumulated value of flow beat in } \\
\text { construction process } \mathrm{C}\end{array}$ & & & 4 & 9 & 12 & 17 & & & \\
\hline $\begin{array}{l}\text { Accumulated value of flow beat in } \\
\text { construction process } D\end{array}$ & & & & 3 & 7 & 9 & 12 & & \\
\hline $\begin{array}{l}\text { The difference between the series } \\
\text { subtraction of construction } A \text { and } B\end{array}$ & 3 & 3 & 6 & 8 & -10 & & & 8 & $\mathrm{~K}_{\mathrm{A}, \mathrm{B}}=8$ \\
\hline $\begin{array}{l}\text { The difference between the series } \\
\text { subtraction of construction } B \text { and } C\end{array}$ & & 2 & 1 & -2 & 2 & $\begin{array}{r}-1 \\
7 \\
\end{array}$ & & 2 & $\mathrm{~K}_{\mathrm{B}, \mathrm{C}}=2$ \\
\hline $\begin{array}{l}\text { The difference between the series } \\
\text { subtraction of construction } C \text { and } D\end{array}$ & & & 4 & 6 & 5 & 8 & -12 & 8 & $\mathrm{~K}_{C D}=8$ \\
\hline
\end{tabular}

(4) Calculate the flow construction period:

$\mathrm{T}=\sum \mathrm{K}_{\mathrm{i} \cdot \mathrm{i}+1}+\mathrm{T}_{\mathrm{N}}=(8+2+8)+(3+4+2+3)=3$ (day)

(5) Drawing irregular flowing water construction schedule

From the above calculation can draw the case of the irregular flowing water construction bar charts shown in the solid line part, where the double arrow represents the two adjacent construction process flow pace (see Figure 1).

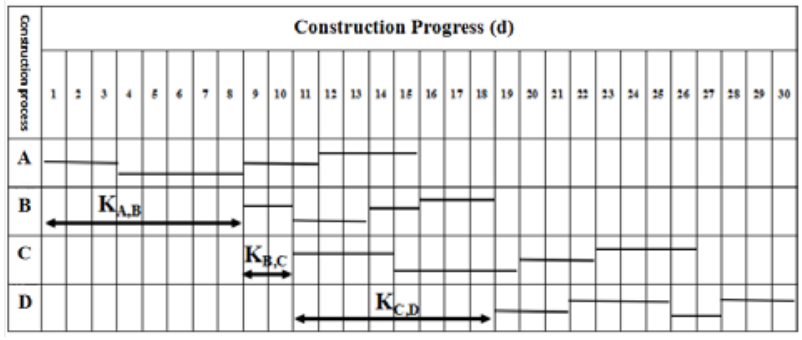

Figure 1: Bar chart of the case

\section{Activity-on-arrow network calculation and processing of irregular flowing water construction}

Network computing is one of the major research areas during the period of the 13th Five-Year Plan of the National Economic and Social Development of the People's Republic of China (2016-2020). The Ministry of Construction of China promulgated the Technicall Specification for Engineering Network Planning and Scheduling (JGJ/T 121-2015), which enabled the engineering network planning technology to follow a unified technical standard in the actual application of plan preparation and control management, thus ensuring that the plan is preciseness and plays an important role in promoting the scientific management of construction projects $^{[5]}$. In many cities, network planning technology has become an important project management approach in construction management.

Generally, the network schedule needs to add time parameters to the network diagram for calculation. The purpose is to determine the critical lines and key work, to clarify the maneuverability of non-critical work and to further co-ordinate the deployment of resources as a whole. Irregular flowing water construction in the network computing needs to deal with the difference issues between the construction period drawn by bar charts and the construction period drawn by the network diagram. The empirical research draws the conclusion that: where flow pace varies from each other, the flow pace must be introduced into the logic of networked computing in the form of virtual work ${ }^{[6]}$. From activityon-arrow network schedule of irregular flowing water construction in the garden project can be analyzed, in order to clarify the logical relationship between the construction sequence, the smooth operation of the construction team for continuous operation, the same way also needs to take virtual work, at the same time, as a logical relationship inserted into activity-on-arrow network diagram to ensure the construction process is continuous; and adding virtual work makes the construction more rigorous, further more, it avoids duration inconsistent between bar chart and activity-onarrow network diagram.

In this case of garden engineering, the special treatment in activity-on-arrow network diagram of flow construction is to add multiple virtual jobs, specifically adding node 7 in the post work of B1 to form 3-7 and 67 virtual work. Empathy, also inserted nodes 9, 11, 14, 16,18 formed the corresponding virtual work, and then 
use the two time-tagging method, making the construction period calculated by activity-on-arrow network diagram and the duration shown in bar chart of the same. In this case, there are three critical lines, which are expressed in bold double arrows (see Figure 2).

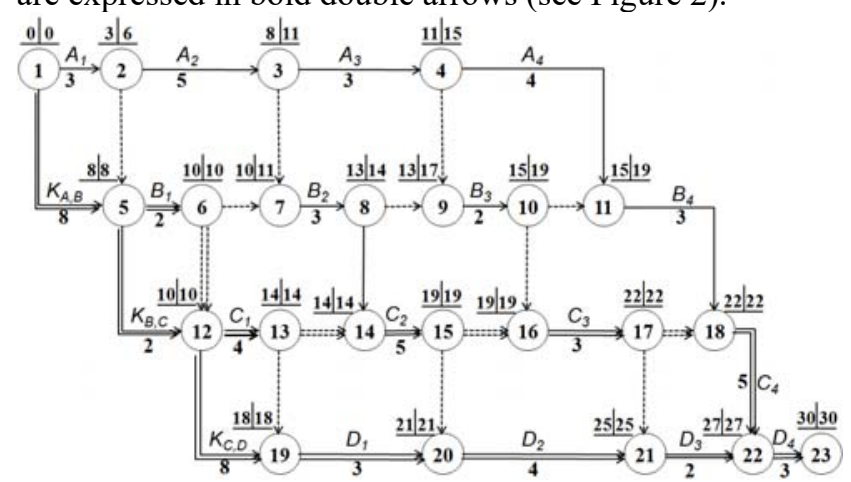

Figure 2: Two time-tagging calculation of activity-on-arrow network diagram of the case

\section{Conclusion}

(1)The case of irregular flowing water construction of the garden project through the calculation of the general flow construction principle, adding a number of virtual work in the calculation of the two time-tagging parameters in activity-on-arrow network diagram so that the logic relationship of the flow pace is rigorous and is conducive to the construction process and maintain the construction team collaboration and continuous operation.

(2)The original plan drawn and calculated by the network plan will lay a solid foundation for the later period, which gives a definite time concept for future project optimization, cost optimization and resource optimization in the process of dynamic implementation of gardening construction management, and provides reference value for network plan adjustment.

\section{References}

1. Pan Li, Fan Juyu. Garden engineering construction management $[\mathrm{M}]$. Beijing: Peking University press, 2013:7

2. Wang Shouxu . Highway Construction Organization and Project Budge 3rd[M].Beijing: China Communications Press, 2007:27-35.

3. The National Construction Enterprise Project Manager Training Textbook Compilation Committee . The Construction Organization Design and Progress Managemen Revised[M].Beijing: China Architecture and Building Press, 2001: 21-45

4. Wei Daosheng.Essence of Difference in Flow Duration in Different Flow Construction[J]. Journal of Chongqing Jiaotong University (Natural Science Edition),2013,32 (3):451-452

5. Cao Hui, Zhang Jiangcheng. Construction Engineering Construction Organization [M]. Beijing:Beijing Publishing House,
6. Li Lan.An Empirical Study on the flow construction Special Problems of Network Planning in Construction Project[J].Building economy, 2013(03):35-38 